\title{
Emancipação, Expulsão e Exclusão: Visões do Negro no Brasil e nos Estados Unidos nos anos 1860
}

\author{
Maria Clara Sales Carneiro Sampaio ${ }^{1}$
}

\begin{abstract}
Resumo: A partir de um despacho enviado por James W. Webb (Ministro Plenipotenciário dos Estados Unidos no Rio de Janeiro entre 1861 e 1869) para William H. Seward (Secretário de Estado dos Estados Unidos na Administração Lincoln), acerca da possibilidade de abrir negociações com o governo brasileiro no tocante à constituição de uma empresa binacional para colonização da Amazônia com população ex-escrava norte-americana, tenciona-se discutir algumas formas discursivas sobre a maneira como Webb via as relações raciais no Brasil. O objetivo deste artigo, entretanto, não é apenas analisar o olhar estrangeiro sobre o Brasil, mas refletir de que forma o olhar de Webb é também um observatório rico para a reflexão sobre a aguda realidade de transformações do equilíbrio racial nos Estados Unidos em plena Guerra da Secessão.

Palavras-Chave: Abolição da Escravidão, Guerra da Secessão, Abraham Lincoln, Relações de Raça e Diplomacia BrasilEstados Unidos.
\end{abstract}

Abstract: The present article intends to analyze a dispatch sent by the plenipotentiary minister of the United States in Brazil during the decade of 1860s, James W. Webb, to the Abraham Lincoln's State Secretary, William H. Seward in the matter of the negotiation with the Brazilian Government involving the constitution of a binational colonization company for the Amazon River Valley using as target population former slaves from United States. The referred document contains a great deal of personal impressions of Webb regarding racial relations in Brazil, but it also can potentially reveal interesting views of the changing scenario of racial balance in United States during Civil War.

Key-Words: Emancipation of Slavery, Civil War, Abraham Lincoln, Race and Diplomatic History of Brasil and United States

\section{Introdução}

O presente artigo faz parte das reflexões que resultaram da dissertação de mestrado, Fronteiras Negras ao Sul: A Proposta dos Estados Unidos de Colonizar a Amazônia Brasileira com Afro-Descendentes Norte-Americanos na Década de 1860, defendida recentemente ${ }^{2}$. O estudo realizado teve como tema a análise da negociação entre os governos do Brasil e dos Estados Unidos - este último representado por seu Ministro Plenipotenciário designado para a embaixada no Rio de Janeiro, James Watson Webb - no que toca a proposta norteamericana de constituição de uma empresa binacional de colonização para Amazônia, com população de libertos norte-americanos. O referido projeto comercial foi apresentado ao então Ministro de Estado dos Estrangeiros do Brasil, Marquês de Abrantes, em maio 1862. Poucos meses depois o Imperador Pedro II mandou responder negativamente ao projeto ${ }^{3}$.

\footnotetext{
${ }^{1}$ Maria Clara Sales Carneiro Sampaio é graduada em Direito pela PUC-SP, graduada e mestre em História pela FFLCH-USP e doutoranda em História Social no departamento de História da USP.

2 SAMPAIO, Maria Clara Sales Carneiro. Fronteiras Negras ao Sul: A Proposta dos Estados Unidos de Colonizar a Amazônia Brasileira com Afro-Descendentes Norte-Americanos na Década de 1860. Dissertação de Mestrado, FFLCH, USP, 2009.

${ }^{3}$ Faz-se importante mencionar que o tema é praticamente inédito no Brasil. Até o presente as menções mais conhecidas sobre o a assunto são de HOLANDA, Sérgio Buarque de. Prefácio. In: LUZ, Nícia Vilela. $\boldsymbol{A}$ Amazônia para os Negros Americanos: Origens de uma controvérsia internacional. Rio de Janeiro: Saga, 1968, p. 11 e os recentes trabalhos de MACHADO, Maria Helena Pereira Toledo. Brasil a Vapor: Raça, Ciência e Viagem no Século XIX. Tese de Livre-Docência, FFLCH-USP, 2005, p. 37 e

(Ed.). Brazil Through the Eyes of William James: Letters, Diaries and Drawings, 1865-1866. Cambridge: David Rockefeller Center for Latin American Studies/ Harvard University Press, 2006, pp. 127136.
} 
Os esforços iniciais da pesquisa foram no sentido de compreender melhor o contexto no qual se desenrolaram as negociações diplomáticas e as circunstâncias que impediram que tal empresa se concretizasse. A procura pelo estabelecimento da historicidade e da pluralidade desse evento se revelou um excelente observatório da circulação de idéias de raça, escravidão e liberdade nos canais oficiais dos governos brasileiro e norte-americano.

A escolha do documento do qual partirá esta análise respeitou a presença de observações pessoais de Webb sobre alguns temas raciais da formação social brasileira. Trata-se da cópia pessoal do próprio Webb de um despacho oficial enviado à Secretaria de Estado em Washington com a data de 10 de maio de $1862^{4}$. O Despacho 17 é uma espécie de relatório analítico sobre algumas questões da organização e da distribuição da mão-deobra - escrava e livre - em alguns setores da economia brasileira, bem como sobre os espaços sociais ocupados pelos libertos nessa sociedade. $O$ intuito era apresentar um primeiro esboço jurídico, econômico e, de certa forma, ideológico, para a criação da referida empresa, além de ser um pedido expresso de autorização ao governo dos Estados Unidos para dar início às negociações com o Brasil ${ }^{5}$.

\section{As Circunstâncias da Elaboração do Despacho 17}

Antes de adentrarmos a análise das impressões de Webb acerca da realidade racial brasileira, e como essa percepção se faz igualmente interessante para perceber as mudanças sociais nos Estados Unidos às vésperas da emancipação geral, faz-se necessário esclarecer brevemente o sentido do Despacho 17 e o projeto político que ele representava ${ }^{6}$. Sua vinda

\footnotetext{
${ }^{4}$ Os documentos de Webb foram consultados na Universidade de Yale, Seção de Arquivos e Manuscritos Raros, James Watson Webb Papers (Doravante referida como UY - SAMR - JWWP). Esse despacho não recebe numeração na cópia pessoal, mas na sua posterior publicação no New York Times, em 28 de dezembro de 1862, aparece a numeração 17, por isso ele será referido daqui em diante como Despacho 17. A resposta do Secretário de Estado William H. Seward foi publicada conjuntamente. Ver SEWARD, William H. WEBB, James W. Negro Colonization: Brazil Proposed by Our Minister as a Field for Colonization. The New York Times, 28/12/1862. Disponível em: http://query.nytimes.com/ mem/ archivefree/pdf? res=9800EFD913 31E03ABC4051DFB4678389679FDE. Consultado em: 17/05/2008.

5 “Dispatch 17 to the Hon. W. H. Seward": UY - SAMR - JWWP, Caixa 8, Pasta 99.

6 A abolição da escravidão no contexto da Guerra da Secessão é um fenômeno cheio de particularidades. Num primeiro momento, imediatamente após a eleição de Abraham Lincoln, a plataforma política do Partido Republicano era simplesmente confinar o instituto nos estados que haviam se juntado à Constituição com o objetivo de manter sua mão-de-obra cativa. Com a separação política dos Estados Confederados da América e, logo depois, o início do conflito civil, uma primeira Proclamação de Emancipação entrou em vigor $1^{\circ}$ de janeiro de 1863, mas esta apenas concedia a liberdade para os escravos dos estados rebelados, quais sejam: Texas, Louisiana, Mississipi, Alabama, Flórida, Geórgia e Carolina do Sul (Os estados do Arkansas, Carolina do Norte, Virgínia e Tennessee só se rebelaram depois do início da Guerra). Em termos práticos, como o governo central, a União, não tinha controle sobre essas áreas, não havia como garantir de fato a libertação desses escravos. A abolição geral nos estados escravistas que lutaram ao lado de Washington só se deu ao final da Guerra da Secessão. Em 1863, o Secretário de Estado, William Seward, referiu-se à Proclamação, como um diploma ineficaz: "our sympathy with the slaves by emancipating the slaves where we cannot reach them and holding them in bondage where we can set them free" SEWARD, William Henry, s/d apud BENNETT, Lerone. Forced Into Glory: Abraham Lincoln's White Dream. Chicago: Johnson Publishing Company, 2000, pg.
} 
ao Brasil se deu no contexto do início da Guerra Civil norte-americana (1861-1864) e, por este motivo, suas funções oficiais tinham de respeitar o delicado momento interno que seu país atravessava ${ }^{7}$. Para além da missão de solidificar o apoio diplomático do Rio de Janeiro à União - haja visto que a posição oficial do Império frente à Guerra da Secessão era a de neutralidade completa, à moda da Inglaterra, que reconhecia diplomaticamente os Estados Confederados da América com o status de beligerantes ${ }^{8}$ - Webb também pretendia negociar outras questões, tais como a compra de terras no Vale do Rio Amazonas com o objetivo de constituir uma empresa binacional de colonização para a exploração da área com mão-de-obra liberta (ou em vias de emancipação) proveniente dos Estados Unidos? .

Esse projeto de colonização da Amazônia desenhado por Webb, é preciso pontuar, diz respeito a um processo muito particular da política de Washington nos primeiros anos da

380. Ver também McPHERSON, James M. The Negro's Civil War: How American Blacks Felt and Acted during the War for the Union. Nova York: Vintage Civil War Library, 2003, pp. 234 a 237.

7 Grosso modo, a Guerra da Secessão opôs as regiões Norte e Sul dos Estados Unidos. O conjunto dos estados aliados ao projeto político do Norte era chamado de União, enquanto os estados rebelados do Sul haviam se separado com o nome de Estados Confederados da América. Os estados que apoiaram a eleição de Lincoln e mais tarde fizeram parte da União foram: Califórnia, Connecticut, Delaware, Illinois, Indiana, Iowa, Maine, Nova Hampshire, Vermont, Massachusetts, Rhode Island, Pensylvania, Nova Jersey, Nova York, Maryland, Ohio, Michigan, Kentucky, Kansas, Kentucky, Minnesota, Missouri e Oregon. Já durante o conflito, os estados de Nevada e Virgínia do Oeste se juntaram a Washington. A lista dos estados confederados está descrita na nota anterior. Apenas como esclarecimento cumpre pontuar que os confederados advogavam em favor da manutenção e expansão da escravidão como uma das bases produtivas de sua economia, enquanto a maioria dos estados da União se amparavam historicamente no desenvolvimento comercial e industrial talhados majoritariamente sobre o trabalho livre. Desde a independência do país, oito décadas antes, a grande parte dos estados do Norte, em especial da região nordeste, havia abolido o pouco trabalho escravo que tinham. EISENBERG, Peter Lois. Guerra Civil Americana. São Paulo: Brasiliense, 1999, pg. 43 a 69.

${ }^{8}$ Vide AHPIRJ, "Notas Expedidas", volume 12, Estante 230, prateleira 2. "Sua Majestade o Imperador, attendendo aos interesses do commércio de seus subditos, e desejando observar uma restrícta neutralidade durante a guerra que infelizmente existe entre os Estados Unidos e os Estados Confederados da América, houve por bem, de conformidade com os princípios do direito internacional, adotados no Império em circunstâncias análogas, ordenar que fosse dirigida aos presidentes das províncias do norte do Império a circular inclusa por cópia. (...) Se bem não reconheça o governo imperial a existência política dos Estados Confederados, não lhes pode, no entanto, recusar o direito de belligerantes, e é este o pensamento daquella circular. De acordo com este pensamento, rogo a V. Ex. haja de expedir as convenientes ordens e instruções às autoridades $d$ Império, que lhes são subordinadas"

9 Algumas considerações sobre as atividades de Webb merecem ser feitas. Webb assumiu em caráter de urgência a Legação dos Estados Unidos no Rio de Janeiro em substituição a Richard K. Meade (que era simpatizante dos confederados e tinha conquistado a simpatia do Imperador Pedro II em seus discursos sobre a proximidade dos dois países então escravistas). Uma de suas primeiras ações foi comunicar aos cônsules norte-americanos em todo o território brasileiro que fiscalizassem as embarcações navegando com bandeira norte-americana de modo que todos os capitães tivessem que jurar obediência à Constituição dos Estados Unidos, sob pena de serem presos e substituídos imediatamente. A questão da fiscalização dos portos brasileiros para tentar impedir que aportassem quaisquer embarcações da Confederação foi um dos temas mais recorrentes da política de Webb, até porque era sabido que o Brasil tolerava esse comportamento. Seu padrão de atuação pode ser rapidamente percebido no acontecido do dia 6 de setembro de 1861, quando o vapor de guerra Sumter, ligado aos confederados, teve permissão para aportar no Maranhão, sob protestos do cônsul norte-americano no local. Webb agiu imediatamente, sem esperar qualquer instrução de Seward. Não conseguindo impedir que a embarcação se abastecesse, enviou nota de repúdio ao Ministério dos Estrangeiros, estabelecendo um padrão que se tornaria cada vez mais comum no cotidiano da sede do Ministério no Rio de Janeiro. Arquivo Histórico do Palácio Itamaraty do Rio de Janeiro (doravante AHPIRJ), "Notas Recebidas", volume 6, estante 230, prateleira 8. Ver também CROUTHAMEL, James L. James Watson Webb: A Biography. Middletown: Wesleyan University Press, 1969, pp. 163-164. 
Guerra da Secessão: conquanto a circulação de idéias de colonização de afro-descendentes fora dos Estados Unidos se mostrou muito presente em toda a primeira metade do século XIX, a discussão dessas idéias e as iniciativas a respeito encontravam seus representantes e entusiastas majoritariamente em organizações privadas e raras vezes se travestiam de programas de governo $^{10}$. A investigação da proposta comercial feita ao Brasil acabou por apontar que o projeto amazônico de Webb fazia parte, na verdade, de uma realidade de negociações múltiplas dos norte-americanos com diversos países da América Central e da América do Sul. Assim, a presença de variados projetos de colonização debatidos no início do Governo Lincoln pode ser interpretada como uma tentativa de apropriação dessa discussão no sentido de transformá-la em uma política de Estado, uma diretriz binomial de combinação necessária da emancipação dos escravos com a colonização dos mesmos fora do país ${ }^{11}$.

\section{Algumas Considerações dos Primeiros Anos do Governo Lincoln}

O significado da vitória republicana de Abraham Lincoln nas eleições presidenciais norte-americanas em 1860 faz-se importante ressaltar de forma breve, representou de inicio uma resistência à expansão e reprodução do sistema escravista do Sul, e não revelou, a princípio, uma plataforma política consistentemente abolicionista ${ }^{12}$. Entretanto, a despeito ter vencido com $40 \%$ do voto popular e apoio dos estados do norte e do oeste, a maioria parlamentar - tanto no senado como na câmara - era da oposição, do Partido Democrata, que interpretou a vitória de Lincoln como uma sentença de morte imediata à instituição da escravidão. Por esse motivo, dentre outros, o conflito civil se iniciou a partir de abril de 1861, de forma que toda a presidência de Lincoln se desenvolveu dentro da realidade da Guerra da Secessão ${ }^{13}$.

As pressões do conflito civil e os rumos políticos tomados por Washington recebem freqüentemente uma interpretação histórica que agrupa os rumos finais da guerra

\footnotetext{
${ }^{10}$ Umas das organizações mais importantes é a American Colonization Society, que será melhor tratada adiante. Ver BURIN, Eric. Slavery and the Peculiar Solution: A History of the American Colonization Society. Miami: University Press of Florida, 2005, pp. 34-47; SANNEH, Lamin. Abolitions Abroad: American Blacks and the Making of Modern West Africa. Cambridge: Harvard University Press, 2001, pp 182-221. 11 SCHOONOVER, Thomas. Misconstrued Mission: Expansionism and Black Colonization in México and Central America During Civil War. The Pacific Historical Review, Vol. 49, No 4, 1980, pp. 607-620 e DYER, Brainerd. The Persistence of the Idea of Negro Colonization. The Pacific Historical Review, Vol 12, No 1, 1943, pp. 53-65.

${ }^{12}$ Cumpre pontuar que Abraham Lincoln foi o primeiro presidente a pertencer ao Partido Republicano, que havia sido criado em meados da década de 1850. A base eleitoral dos republicanos eram os estados do Norte e Meio-Oeste e embora abarcasse grupos bastante distintos - que iam desde abolicionistas mais liberais até partidários fervorosos da manutenção da escravidão em alguns estados originalmente escravistas - sua plataforma política de início era confinar a escravidão apenas nas regiões onde a constituição permitia a instituição. Ver McPHERSON, James M. The Negro's Civil War: How American Blacks Felt and Acted during the War for the Union. Nova York: Vintage Civil War Library, 2003, pp. 3 a 18.

13 McPHERSON, James M. Battle Cry of Freedom: The Civil War Era. Nova York: Oxford University Press, 2003, pp. 6-46.
} 
e da emancipação da escravidão sob um prisma monolítico dos valores do abolicionismo e das políticas de equalização social dos libertos no período da Reconstrução ${ }^{14}$. A inclusão social dos emancipados, contudo, não parecia ser tão priorizada na plataforma política do governo nos anos 1861 e 1862, eram as iniciativas de colonização de afro-descendentes fora do território dos Estados Unidos que pareciam receber maior apoio de Lincoln. Como exemplo, pode-se citar a publicação na primeira página do New York Tribune, de 15 de agosto de 1862, da discussão que se fazia no governo sobre um projeto de transferência de libertos para regiões ao sul da fronteira do México ${ }^{15}$.

\begin{abstract}
O local onde penso em ter uma colônia é na América Central. É mais próxima de nós que a Libéria - não muito mais que um quarto da distância da Libéria e a apenas sete dias de viagem de vapor. Ao contrário da Libéria é uma travessia tranqüila - é uma via expressa. A terra é excelente para qualquer povo, com amplos recursos naturais e vantagens, especialmente a semelhança climática com sua terra natal, sendo, portanto, adequada às suas condições físicas ${ }^{16}$.
\end{abstract}

Assim, a questão da colonização de afro-descendentes durante a Guerra da Secessão era tema de substancial relevância na agenda do governo dos Estados Unidos. Diversos membros do gabinete de Lincoln estavam envolvidos com essa questão. Lerone Bennet cita Gideon Welles, o então Secretário da Marinha: "Desde o início desta administração... o assunto da deportação da raça de cor tem sido discutido"17. Cumpre pontuar que uma comissão especial para tratar desse assunto foi criada e delegada ao Senador Samuel Clark Pomeroy, do Kansas, que foi nomeado Colonization Agent de Lincoln, em $1862^{18}$. No mesmo ano, o Congresso dos Estados Unidos atendeu ao pedido de Lincoln para que fosse aprovado o orçamento no valor de US\$ 600.000, para dar continuidade à guerra civil e para iniciar processo de colonização de afro-descendentes fora das fronteiras do país. No final do

\footnotetext{
14 A Reconstrução norte-americana compreende o período entre os anos 1863 e 1877, quando o Norte desagregou politicamente os confederados e promoveu grandes mudanças nos estados do Sul. Uma das transformações impostas foi o reconhecimento jurídico da igualdade civil dos libertos. Na década de 1880, grande parte dos estados do Sul aboliu as práticas de equidade racial, substituindo-as por políticas de segregação. FONER, Eric. Reconstruction... pp. 239 a 251.

${ }^{15}$ HORNE, Gerald. The Deepest South: The United States, Brazil and the African Slave Trade. Nova York: New York University Press, 2007, p. 174 e BENNETT, Lerone. Forced Into Glory: Abraham Lincoln's White Dream. Chicago: Johnson Publishing Company, 2000, p. 459.

16 "The place I am thinking about having for a colony is in Central America. It is nearer to us than Liberia - not much more than one fourth as far as Liberia, and within seven days run by steamers. Unlike Liberia it is on a great line of travel - it is a bighway. The country is a very excellent one for any people, and with great natural resources and advantages, and especially because of the similarity of climate with your native land - thus being suited to our physical condition". LINCOLN, Abraham. The Colonization of People of African Descendent. New York Tribune, 15/08/1982 in BENNETT, Lerone. Forced Into Glory... p. 459. (Tradução nossa).

17 "Almost from the commencement of this administration... the subject of deporting colored race has been discussed WELLES, Gideon, s/d apud BENNETT, Lerone. Forced Into Glory... p. 380. (Tradução nossa).

${ }^{18}$ GRESHAM, Luveta W. Colonization Proposals for Free Negroes and Contrabands During Civil War... p. 33.
} 
mesmo ano, no corpo da mensagem anual da Presidência, Lincoln apresentou um plano de emancipação gradual e compensatória dos escravos, combinado com um plano de migração voluntária para os libertos ${ }^{19}$.

A abolição geral nos Estados Unidos, pelo menos no início da Guerra da Secessão, parecia respeitar uma lógica de desconstruir a instituição da escravidão a partir de uma combinação necessária com a retirada dos ex-escravos do convívio social e político do país $^{20}$. As declarações presidenciais públicas refletiam, é preciso reafirmar, a noção de colonização como uma conseqüência, uma necessidade, gerada pela emancipação ${ }^{21}$. A comunhão das duas idéias advinha da crença geral de que a convivência com os escravos, libertos e seus descendentes, em igualdade de direitos com os brancos, era uma impossibilidade social para a realidade norte-americana ${ }^{22}$. As concepções que embasavam esse ideário são descritas por Robert L. Gold - como um "pensamento oitocentista pseudo-científico", que atava o desenvolvimento possível do africano às regiões tropicais ${ }^{23}$ - revelava, em verdade, não só a forma como os norte-americanos percebiam as relações de raça e escravidão no restante da América, mas iniciativas claramente imperialistas de influenciar novos territórios ${ }^{24}$.

\section{As Idéias e Teorias Racialistas e a "Impossibilidade" de Assimilação Social do}

\section{Afro-Descendente}

Cumpre introduzir que os anos que circundaram a Guerra da Secessão foram particularmente profícuos para o debate sobre a escravidão, abolição e o lugar dos afrodescendentes nessa sociedade, haja vista que o conflito entre o Norte e o Sul precipitou justamente uma nova configuração política e social onde as idéias e teorias racialistas tiveram grande importância. O papel da ciência norte-americana, neste momento, merece algumas breves considerações. O debate norte-americano sobre o tema da raça da primeira metade do século XIX foi bastante plural e permeou grande parte dos diversos círculos das elites - do Sul e do Norte - ocupados em pensar os rumos da escravidão e a presença das comunidades de libertos em algumas regiões. O poligenismo e a teoria da degeneração, em

\footnotetext{
${ }^{19}$ BENNETT, Lerone. Forced Into Glory...p. 380

${ }^{20}$ Ver capítulo 9 de HORNE, Gerald. The Deepest South...

21 McPHERSON, James M. Abolitionist and Negro Opposition to Colonization during the Civil War. Phylon, Vol. 26, No. 4 (1965), pp. 392-396.

22 SANNEH, Lamin. Abolitions Abroad... pp. 22- 64.

23 GOLD, Robert L. Negro Colonization Schemes in Ecuador, 1861-1864. Phylon, Vol. 30, N. 3, 1969, p. 307,309 .

${ }^{24}$ Sobre as teorias raciais cientifiscizadas que ganharam grande importância nos Estados Unidos nesse momento ver o capítulo 1 de MACHADO, Maria Helena Pereira Toledo. Brasil a Vapor: Raça, Ciência e Viagem no Século XIX...
} 
especial, galgaram muita importância tanto nos grupos defensores do escravismo, quanto daqueles que viam na instituição uma incompatibilidade fundamental com $\mathrm{O}$ desenvolvimento social e político dos Estados Unidos.

\begin{abstract}
Os poligenistas (...) acreditavam que a humanidade não era una, mas formada por diferentes espécies, tendo havido mais de uma criação divina, (...) a teoria da degeneração que rezava que a miscigenação entre as diferentes raças humanas ou o hibridismo levava à degenerescência. A base desta crença era que as raças cruzadas, em vez de carregarem as melhores características de seus ancestrais, levavam a que traços atávicos viessem à superfície, expondo os descendentes de uniões mistas a todos os riscos de uma progressiva degenerescência. (...) A idéia de que diferentes raças humanas houvessem sido criadas para habitar províncias zoológicas específicas, estando portanto aptas a responder apenas aos desafios de seu meio ambiente, encontrava sua base no poligenismo ${ }^{25}$.
\end{abstract}

Assim, faz-se necessário apontar que essas idéias de colonização de libertos fora dos Estados Unidos não só não foram uma novidade circunstancial da Guerra de Secessão, como estavam em perfeita consonância com alguns dos rumos do pensamento racial e científico. A escolha das localidades para abrir áreas de assentamento dos libertos freqüentemente são envolvidas por argumentos que atrelam ao clima tropical - da África, da América Central e América do Sul - as possibilidades de melhor desenvolvimento dos afro-descendentes ${ }^{26}$.

Um exemplo da apropriação dessas teorias na construção de argumentos relativos aos planos de colonização de libertos no início do Governo Lincoln é o caso da proposta do próprio Webb feita ao Brasil: "A grande necessidade do Brasil no momento é mão de obra. Pelas características de seu clima e solo, o trabalho negro é preferivel ao branco, e como o trabalho livre é mais sedentário e não pode ser removido das regiões onde se acomodou, o trabalho negro livre é preferivel ao trabalho escravo, ${ }^{, 27}$.

Nesse mister, é interessante observar que desde as primeiras décadas do século XIX, as idéias de colonização transitavam intensamente em diversos setores ideológicos dos

\footnotetext{
${ }^{25}$ MACHADO, Maria Helena Pereira Toledo (Ed.). Brazil Through the Eyes of William James: Letters, Diaries and Drawings, 1865-1866... p. 149.

${ }_{26}$ Um exemplo da apropriação dessas teorias na construção de argumentos relativos aos planos de colonização de libertos no início do Governo Lincoln é o caso da proposta feita ao Brasil: "The great want of Brazil of this day is labour. From the character of her climate and soil, Black. labour is preferable to white, and because free labour is more stationary, and cannot be removed from the regions to which it has accommodated itself, Free Black labour, in a National point of view, is preferable to slave labour". "On the necessity of supplying Brazil with Labour; and the policy of procuring free Black Labour from the United States": UY - SAMR - JWWP, Caixa 8, Pasta 102, In: SAMPAIO, Maria Clara Sales Carneiro. Fronteiras Negras ao Sul: A Proposta dos Estados Unidos de Colonizar a Amazônia Brasileira com afro-descendentes norte-americanos na década de 1860 ... p. 48.

27 "The great want of Brazil of this day is labour. From the character of her climate and soil, Black, labour is preferable to white, and because free labour is more stationary, and cannot be removed from the regions to which it has accommodated itself, Free Black labour, in a National point of view, is preferable to slave labour" "On the necessity of supplying Brazil with Labour; and the policy of procuring free Black Labour from the United States": UY - SAMR JWWP, Caixa 8, Pasta 102. (Tradução nossa).
} 
Estados Unidos e impulsionavam importantes movimentos sociais. Um exemplo disso é a fundação da American Colonization Society, em 1816, com o objetivo de abrir áreas de colonização para ex-escravos na costa oeste da África. A conseqüente criação da Libéria, nos anos $1820^{28}$, é a primeira experiência prática de remoção de ex-cativos dos Estados Unidos $^{29}$.

Defensores do reassentamento de negros sugeriram várias localidades no exterior para a colonização. Logo antes da guerra civil, o senado dos Estados Unidos cogitou resoluções para requerer a aquisição de privilégios de assentamento no México e na América do Sul. Alguns anos mais tarde, em 1861-1862, as Américas Portuguesa e Espanhola pareciam particularmente atraentes para a colonização. Durante a maior parte do século XIX, as repúblicas do Haiti e Libéria agradavam os adeptos da deportação. Durante os anos da guerra, o presidente Lincoln chegou a contemplar a possibilidade de assentar libertos na Flórida e no Texas. Até a remota Austrália foi mencionada como uma possível localidade para colônia de negros americanos ${ }^{30}$.

Para além da África, muitas outras regiões, como mencionado na referência acima, foram cogitadas, mais tarde, para receber ex-escravos provenientes dos Estados Unidos, notadamente na América Central e na América do Sul, o que nos leva a pensar que essas idéias de colonização de afro-descendentes podem ser consideradas uma constante do desenvolvimento histórico dos Estados Unidos no século XIX e são um termômetro interessante para pensar a forma como o afro-descendente livre é visto nessa sociedade ${ }^{31}$. Neste sentido, novamente, é possível supor que o Governo Lincoln apenas tentou

${ }^{28}$ BURIN, Eric. Slavery and the Peculiar Solution: A History of the American Colonization Society. Miami: University Press of Florida, 2005, p. 141. Na verdade 1821 é ano em que a American Colonization Society adquiriu a primeira porção de terra na localidade que viria a ser a Libéria.

29 Parece razoável pensar que o pouco êxito do projeto original da Libéria poderia ter justificado um resfriamento dessas idéias de colonização, e não tanto seu fortalecimento e transformação em política de Estado tantas décadas depois. Consta que nas primeiras décadas de existência, a colônia norte-americana na África recebeu, entre os anos 1820 e 1830, o irrisório número de 3.160 imigrantes. Até o início da década de 1860, mais 7.779 chegaram ao território. Os números são de SANNEH, Lamin. Abolitions Abroad: American Blacks and the Making of Modern West Africa. Cambridge: Harvard University Press, 2001, pp. 198-202, mas outros números aparecem em outras obras, um exemplo é o caso do artigo de BELL, Howard H. Negro Nationalism: A Factor in Emigration Projects, 1858-1861, que apresenta o número 11.000. A estimativa de Sanneh se parece muito com a de BURIN, Eric. Slavery and the Peculiar Solution... p. 170, Tabela 2 "ACS emigration by period, 1820-1860".

30 "Advocates of the resettlement of Negroes suggested a variety of areas abroad for colonization, Immediately before the Civil $W$ ar, the United States Senate considered resolutions urging the acquisition of settlement privileges in Mexico and/or Central and South America. Several years later, in 1861-1862, Spanish and Portuguese America seemed especially attractive for colonization. Throughout most of the nineteenth century, the Republics of Haiti and Liberia continually appealed to the adherents of deportation. In the war years, President Lincoln contemplated briefly the possibility of settling freedmen in Florida and Texas. Even faraway Australia was mentioned as a possible location for a Negro American colony". GOLD, Robert L. Negro Colonization Schemes in Ecuador, 1861-1864... p. 307. (Tradução nossa)

${ }^{31}$ Ver DYER, Brainerd. The Persistence of the Idea of Negro Colonization...pp. 53-65. A forma como o afro-descendente é visto nos Estados Unidos do século XIX é um dos assuntos amplo demais para começar a ser enfrentado neste artigo. Essa reflexão se insere na ampla discussão da predominância da cultura anglosaxônica na formação nacional do país que, em muitas medidas, tem parte dos eixos de problemas desenvolvidos em processos históricos posteriores ao período que se pretende analisar. 
materializar, como política de Estado, essas idéias que vinham circulando no país há muito tempo devido às circunstâncias específicas da Guerra da Secessão.

Para se compreender melhor os contornos do tema faz-se necessário, antes, atentar para alguns processos históricos particulares dos Estados Unidos. É preciso notar que a experiência do afro-descendente nos Estados Unidos é bastante singular em pelo menos dois aspectos. Em primeiro lugar, desde a independência norte-americana, no final do século XVIII, abriu-se um precedente inédito na história da condição dos afrodescendentes no continente americano: a possibilidade de alistamento militar, em ambos os lados do conflito, com a promessa de liberdade e, eventualmente, terras para cultivo ${ }^{32}$. Tal circunstância gerou uma comunidade de libertos expressiva no país.

Por outro lado, a força de trabalho norte-americana sempre foi, comparativamente a outros países americanos, mais diversificada. O regime de trabalho escravo era predominante apenas em algumas regiões, notadamente no Sul. $O$ trabalho livre de nacionais e imigrantes europeus era, assim, mais fundamental para a economia global dos Estados Unidos. A combinação desses fatores gerou, desde as últimas décadas do século XVIII, mas principalmente na primeira metade do século XIX, uma realidade social de convívio de libertos com outros trabalhadores livres. $\mathrm{O}$ afro-descendente, livre ou escravizado, desta forma, não era, a princípio, a única alternativa mão-de-obra disponível no país ${ }^{33}$. Assim, a estruturação da economia e da sociedade norte-americanas, desde seus primórdios, sobre variados regimes de trabalho é um dos eixos de problematização para pensar a consolidação da noção do afro-descendente livre como um estrangeiro e, como uma conseqüência disto, a constante da idéia de ser necessário removê-lo do território nacional ${ }^{34}$.

Antes de prosseguirmos, faz-se importante, ainda, retomar algumas circunstâncias do processo de independência dos Estados Unidos. Nos anos que seguiram a Revolução Americana, percebe-se que o tema da abolição já era timidamente discutido e um desdobramento possível para uma realidade de emancipação era justamente o estabelecimento de colônias livres fora do território norte-americano, na África, de início.

\footnotetext{
32 FREDRICKSON, George M. The Black Image in the White Mind. The Debate on Afro-American Character and Destiny, 1817-1914. Hanover: Wesleyan University Press, 1987, p. 14.

33 A guerra civil, que durou de 1861-1865, leva a termo uma série de processos históricos relacionados ao equilíbrio racial pós-abolição. Ver FONER, Eric. Reconstruction: America's Unfinished Revolution, 1863-1877. Nova York: Perennial Classics, 2002, pp.78 - 119; e capítulos II e III de LUZ, Nícia Vilela. A Amazônia para os Negros Americanos: Origens de uma controvérsia internacional. Rio de Janeiro, Saga, 1968.

34 Ver MARTIN, Ben L. From Negro to Black to African American: The Power of Names and Naming. Political Science Quarterly, Vol. 106, No 1, 1991, pp. 83-107 e RECORD, Wilson. The Negro Intellectual and Negro Nationalism. Social Forces, Vol 33, No 1, 1954, pp. 10-18.
} 
Como mencionado essas idéias de colonização povoavam todo tipo de grupo das elites políticas do Sul e do Norte, também ganhou alguma força entre os próprios libertos ${ }^{35}$.

A crença que o negro, se libertado, permaneceria um estrangeiro e que sua presença seria incômoda parecia ser confirmada, no início do século XIX, pela situação daqueles negros que, depois de Revolução, tinham sido emancipados no Norte ou pessoalmente alforriados no Sul ${ }^{36}$.

A emancipação dos escravos e a convivência social com os afro-descendentes livres, assim, passaram a ser vistas freqüentemente como realidades que tinham quer ser necessariamente combinadas com a remoção dessa mesma população. Em face ao mencionado, contemplar a proposta de colonização apresentada ao Brasil - bem como as outras apresentadas à América Central e do Sul, nos anos 1861 e 1862 - envolve também refletir sobre o desenvolvimento desse binômio emancipação-colonização. A escolha das localidades no Caribe e na América do Sul, por outro lado, revelam outro feixe de relações e interesses entre os Estados Unidos e América Latina, no tocante não só nos interesses políticos e comerciais do primeiro em relação à última, como na visão que os norteamericanos têm das relações de raça nessas áreas tropicais.

\section{A Cronologia do Projeto Amazônico de Webb}

A princípio, a primeira menção à proposta de criação de uma companhia de colonização e exploração rural da Amazônia por afro-descendentes norte-americanos aparece no Despacho 17, de 10 de maio de 1862. Não se sabe ao certo a data da entrega da proposta ao governo do Brasil, tendo em vista que não foi encontrada cópia de tal documento nos arquivos brasileiros. Sabe-se, entretanto, que em junho de 1862 o Imperador Pedro II já havia tomado ciência dos objetivos de Webb. Nas palavras de Sérgio Buarque de Holanda:

Dom Pedro (...) no diário, porém, que não destinava à publicação (...), com data de 11 de junho de 1862, (...) 'O Abrantes apresentou três propostas do ministro americano, cujo fim é transvasar para o vale do Amazonas principalmente, os negros que se libertassem nos Estados Unidos! O Abrantes ficou de tirar cópias de tão singulares propostas e de responder como convém ao Webb’ (...) Não me ocorreu procurar em fontes documentais brasileiras outras notícias sôbre o projeto. Percorrendo, no entanto, com intuitos diferentes, alguns papéis do volumoso arquivo pessoal do enviado extraordinário e Ministro Plenipotenciário

\footnotetext{
35 SANNEH, Lamin. Abolitionists Abroad... p.12. Já foi introduzido na nota 9 o tema dos emigrationists e do Negro Nationalism.

36 "The belief that the Negro, if freed, would remain an alien and troublesome presence seemed confirmed in the early nineteenth century by the situation of those blacks who, after the Revolution, had been emancipated in the North or manumitted privately in the South FREDRICKSON, George M. The Black Image in the White Mind... p. 4. (Tradução nossa).
} 
do govêrno de Washington junto à corte do Rio de Janeiro, General James Watson Webb, hoje na biblioteca da Universidade de Yale, pude achar dois textos que se relacionam com o projeto: o primeiro intitula-se 'Concessão ao General J. Watson Webb, dos Estados Unidos da América' e o segundo, 'Memorial do General J. Watson Webb, cidadão dos Estados Unidos e ora enviado Extraordinário e Ministro Plenipotenciário do Governo dos Estados Unidos junto à Corte do Brasil, a Sua Majestade Imperial Dom Pedro II, Imperador Constitucional e Defensor Perpétuo do Brasil' (...) Há diferenças, contudo, entre o projeto que se guarda na livraria de New Haven e o plano que teria sido submetido por Abrantes a D. Pedro ${ }^{37}$.

Assim, no breve espaço entre 10 de maio e 11 de junho de 1862, Webb entregou ao Marquês de Abrantes uma minuta de contrato para a abertura de uma companhia de colonização e um memorial anexo com a exposição de razões econômicas, morais e raciais relacionadas à importância do empreendimento. A estreita janela de tempo entre o Despacho 17 e o conhecimento de Dom Pedro II da proposta comercial indica que, muito provavelmente, não tenha havido tempo hábil, por parte da Secretaria de Estado dos Estados Unidos, para responder ao pedido de autorização de Webb para iniciar as negociações com o Brasil. Destarte, podemos inferir pelo menos duas alternativas: ou Webb já chegou ao Brasil incumbido de convencer o Imperador a participar de tal empresa, ou simplesmente não se preocupou em esperar por qualquer autorização oficial, devido à importância que o tema da colonização de afro-americanos vinha ganhando na política de Abraham Lincoln. De qualquer maneira, é preciso apontar que a resposta oficial de William Seward data de 21 de julho de $1862^{38}$. Nela, não autoriza expressamente as negociações, mas não coloca qualquer óbice à continuidade da discussão do tema tanto dentro do gabinete presidencial norte-americano quanto no Brasil. É possível pensar, desta forma, que Webb agiu com certa independência de seus superiores, mas dentro de um contexto no qual a remoção de ex-escravos era assunto de grande importância política cotidiana ${ }^{39}$.

A resposta do Marquês de Abrantes, de 23 de julho de 1862, à proposta de Webb, foi negativa. Trata-se de um despacho curto que não permite grandes contraargumentações.

General, tive o prazer de ler com a máxima atenção os documentos que me confiou e agora lhe dou retorno, em relação ao seu plano de introdução de negros libertos no Brasil. Devo admitir que o objetivo em si é altamente interessante. É minha opinião pessoal que suas idéias merecem consideração e que muitas delas, em circunstâncias favoráveis, em todos os aspectos, seriam de grande utilidade.

37 HOLANDA, Sérgio Buarque de. Prefácio. In: LUZ, Nícia Vilela. A Amazônia para os Negros Americanos: Origens de uma Controvérsia Internacional. Rio de Janeiro: Saga, 1968, p. 11.

${ }^{38}$ Nenhuma cópia desse despacho foi encontrada dentre os arquivos de Webb. Tomou-se conhecimento da mesma pelo já citado New York Times, de 28 de dezembro de 1862, na mesma página onde estava publicado o Despacho 17.

${ }^{39}$ SEWARD, William H. WEBB, James W. Negro Colonization... 
No entanto, nada desta ordem poderá ser tentado em nosso país, pois temos uma lei positiva que impede expressamente a entrada de qualquer negro liberto em nossas fronteiras. Acho cabível fazer chegar ao seu conhecimento esta lei. Aqui segue: "trto Yo (sic) da Lei de 7 de Novembro de 1831, Nao sera permittida a qualquer homem liberto, que mão (sic) for brazileiro, desembarcar nos portos do Brazil, debaixo de que qualquer motivo que seja. O que desembarcar será immediatamente reexportado". Aproveito a oportunidade, caro general, para renovar meus votos de estima e apreço. Abrantes ${ }^{40}$.

Em resumo, os documentos relacionados à proposta de Webb mostram uma proposta de concessão do governo brasileiro do direito de exclusividade de introduzir em todo o território do Império colonos, africanos ou afro-descendentes, emancipados ou em vias de libertação por parte do governo dos Estados Unidos ou por qualquer de seus cidadãos. Tal privilégio seria garantido a Webb e eventuais associados pelo período de 20 anos ou, passado o período, até que revogado o direito por parte do Brasil. Os indivíduos a serem introduzidos na Amazônia trabalhariam, por um período de 5 anos, sob o regime de aprendizado: "As pessoas a serem introduzidas pelo concessionário e seus associados, serão chamadas de "aprendizes"; e seu trabalho por um perído de cinco anos e um mês do dia de deu desembarque no Brasil será propriedade do concessionário \& (sic) seus associados" $"$.

O “aprendizado" é a base econômica e ideológica da companhia almejada por Webb, pois é a forma que o colono tem de pagar pelas despesas da Companhia com o seu transporte e manutenção e é, ao mesmo tempo, a condição de "educação" dos afrodescendentes para a liberdade. Esses valores de liberdade a serem ensinados aos exescravos, na visão de Webb, os tornaria aptos a gozarem com responsabilidade e consciência sua futura cidadania dentro do Império do Brasil, afastando-os definitivamente da convivência civil e política da sociedade norte-americana. Tal argumento, entretanto, reflete muito mais a experiência de outras ex-colônias de atribuir a responsabilidade da emancipação ao próprio escravo, do que a experiência norte-americana com colonos europeus. O aprendizado é, antes de tudo, uma forma de trabalho forçado e dependente

40 "General, I had the pleasure to read with the utmost attention the papers you had the kindness to entrust to me, and now return to you, relative to your plan of introducing freed negroes from United States into Brazil. I must confess that the object in itself is highly interesting. It is my particular opinion that your ideas deserve in a large measure to be seriously pondered; and that many of them, should circumstances be favourable in every respect, would be greatly useful. But nothing of that sort may possibly be tried in our Country, as we have a positive law which expressly interdicts the admittance of any freed Negroes within our limits. I think it suitable to make you know the law which I refer to. Here you bave it: "trto Yo da Lei de 7 de Novembro de 1831, Nao sera permittida a qualquer homem liberto, que mao for brazileiro, desembarcar nos portos do Brazil, debaixo de que qualquer motivo que Seja. O que desembarcar será immediatamente reexportado". I avail myself of this opportunity to renew to you, dear general, the expression of my best regards. Abrantes". From Marquis d'Abrantes: UY - SAMR - JWWP Caixa 8, Pasta 100. Não se trata de uma tradução interna à Legação dos Estados no Rio de Janeiro, a correspondência assinada pelo Marquês de Abrantes já foi entregue escrita em inglês. (Tradução nossa).

41 "The persons to be introduced by the Concessionist and his associates, or their assigns shall be known as "apprentices"; "and their labour for a period of five years \& one month from the day of their landing in Brazil, shall be the property of said Concessionist his associates \& assigns". Concession to General J. Watson Webb of the United States of America: UY - SAMR - JWWP, Caixa 8, Pasta 102. 
que faz com que o ex-escravo custeie sua liberdade e ainda proporcione lucros à companhia de colonização.

\begin{abstract}
O Brasil garante ao colonizador e seus designados que as pessoas introduzidas como colonos sob essa concessão e conhecidos por "aprendizes" irão ser fiéis e prestar serviços à parte ou às partes que os introduziram; irá também adicionar à legislação o que for necessário para assegurar o fiel cumprimento de seus deveres como aprendizes. Após cinco anos e um mês da expiração de sua entrada no Brasil, eles deverão ser liberados de sua condição de aprendizes e se tornarão cidadãos brasileiros do Império do Brasil. E sobre este despacho o concessionário ou a companhia representando por completo o interesse de seu aprendiz, enquanto na condição de aprendiz, e após sua dispensa, solenemente se compromete em fazê-lo por tratado selado com os Estados Unidos ${ }^{42}$.
\end{abstract}

Portanto, a fase de aprendizado significava, em última instância, retirar das mãos do governo dos Estados Unidos os custos sociais e econômicos desse processo de emancipação e expatriação de seus afro-descendentes. Esse era o princípio formador da companhia de Webb: transferir as responsabilidades diretas ligadas ao objeto da empresa "o espírito filantrópico de libertar e ensinar o valor da liberdade através do trabalho" - do governo para um agente mediador privado. Essa manobra não só isentaria os cofres públicos norte-americanos, como deixaria o governo imperial brasileiro mais confortável, já que o controle e a educação da população assentada em seu território seriam exercidos por uma empresa privada, e não por um governo estrangeiro. Claramente esse artifício esconde uma fortemente premissa imperialista.

O afastamento do governo norte-americano da administração da companhia de colonização também implicaria que o empreendimento não deveria ter nenhum custo para seus cofres públicos: cada colono deveria pagar seus gastos com transporte e instalação na Amazônia. Para tornar tudo isso possível, a sugestão de Webb era de que o Congresso dos Estados Unidos aprovasse a criação de uma Companhia de Colonização - uma joint stock ${ }^{43}$ além de indicar o presidente da empresa e um terço dos seus diretores. Sendo ele próprio a

\footnotetext{
42 "Brazil guaranties to the Colonists and his assigns, that the persons introduced as Colonists under this Concession, and known as "apprentices", shall, for the term of their apprenticeship, render faithful service to the party or parties so introducing them; and she will cause such additional Legislation as may be necessary, to insure a faithful discharge of their duties as "apprentices". And at the expiration of the period of Five Years and one month from the day of their introduction into Brazil, they shall be discharged from the apprenticeship, and become Citizens of the Brazilian Empire. And upon such discharge, the Concessionist or the Company representing his interest apprentice in all his rights while an apprentice in all his rights while an apprentice \& after bis discharge, but will by Treaty stipulation with the United States, solemnly bind itself so to do". Concession to General J. Watson Webb of the United States of America: UY - SAMR - JWWP, Caixa 8, Pasta 102.

43 A forma jurídica joint stock é próxima à sociedade anônima brasileira, que tem seu capital dividido em ações a serem vendidas. A responsabilidade de cada acionista é proporcional a valor de suas ações subscritas ou adquiridas, ou seja, os compradores não necessariamente pagam suas ações no ato da compra, podem apenas se comprometeram a pagar futuramente, de forma que o capital previsto no valor da empresa não necessariamente está no fluxo de caixa. MELLO, Maria Chaves de. Dicionário Jurídico Inglês-Português. $8^{a}$ edição, São Paulo, Método, 2007.
} 
ser nomeado o presidente da empresa e a abertura da mesma para o capital privado se daria apenas no mercado de ações dos Estados Unidos, confirmando mais uma vez o impulso imperialista de tornar parte da Amazônia uma zona controlada pelo capital privado norteamericano.

Ainda que o objetivo de Webb fosse isentar o governo norte-americano de despesas e responsabilidade social para com os futuros ex-escravos, o capital inicial da Companhia seria em parte financiado pelos cofres públicos. A proposta inicial era que o capital total da empresa a ser vendido em ações fosse de até US\$3.000.000, entretanto, para cada dólar investido em ações, o governo dos Estados Unidos deveria emprestar à companhia 5\% do valor, a ser integrado com espécie de títulos de dívida pública. A valorização esperada para essas ações, desta forma, aumentaria o capital de giro da empresa, possibilitando o reinvestimento do dinheiro no aumento de seu porte, com objetivo final de expatriar o maior número possível de afro-descendentes.

Ao chegar ao Brasil, os colonos receberiam uma porção de terra disponibilizada pelo governo brasileiro ao longo do Rio Amazonas. Seriam responsáveis pela limpeza do terreno e pela construção de uma pequena cabana. Receberiam algum material de cultivo agrícola e dinheiro em espécie para garantirem que tal propriedade estivesse pronta para o cultivo imediato. Uma vez expirado o prazo de 5 anos, os colonos seriam emancipados e receberiam uma porção dessa terra. Webb acreditava que o governo brasileiro deveria transferir de boa fé para a propriedade da Companhia de Colonização cerca de 100 acres por colono emancipado, que receberia até um quinto do total.

\footnotetext{
Para cada pessoa negra introduzida no Brasil pelo dito Webb e seus associados ou designados, sob esta concessão, por ele ou eles, o governo do Brasil por meio deste se compromete a conceder a ele ou a eles ou à tal Companhia, cem acres de terra escolhida e localizada em terras do governo em tal lugar ou lugares do reino onde o concessionário ou seus designados possam escolher, desde que, em nenhuma circunstância, uma escolha de localidade seja menor que uma milha quadrada inglesa, que consiste de seiscentos e quarenta acres ${ }^{44}$.
}

Assim, a base de cálculo da empresa seria os até $80 \%$ de terra limpa e cultivada, para a qual, novos colonos seriam trazidos continuamente ou, simplesmente, para a venda. É preciso apontar que não trata propriamente de exploração de trabalho escravo, e sim de trabalho dependente. Por isso, os colonos deveriam ser remunerados pelo trabalho no

44 "For every colored person introduced into Brazil by the said Webb and his Associates or assigns, under this Concession, or by him or them the Government of Brazil hereby binds itself, to convey to him or them, or such Company, one hundred acres of land to selected and located (???) upon the land of the Government, at such place or places in any part of the kingdom as the Concessionist or his assigns, may elect, provided however, that in no instance, shall a selection or location be less than one English Mile square, containing six hundred and forty acres". Concession to General J. Watson Webb of the United States of America: UY - SAMR - JWWP, Caixa 8, Pasta 102. 
terreno em tudo aquilo que ultrapassasse os custos da Companhia com seu transporte e instalação. Esse sistema de funcionamento, na opinião de Webb, quadruplicaria o valor do capital inicial investido, e pagaria em pouco tempo os empréstimos obtidos, além de proporcionar grande margem de lucros aos acionistas. A minuta de contrato não fala em números exatos de quantos afro-descendentes seriam trazidos para o Brasil. Entretanto, o Despacho 17 menciona alguns números: "Os Estados Unidos se encontram prontos para investir de imediato de dez a cinqüenta mil de seus trabalhadores treinados e educados no solo brasileiro, sem custo, bastando apenas que o Brasil abra seus braços, para recebê-los e prover por seu futuro conforto" ${ }^{45}$. Outros números bem maiores também foram mencionados, como um milhão.

\section{Uma Proposta de Análise Documental}

Esclarecidos alguns pontos sobre as circunstâncias nas quais foi elaborado o Despacho 17, faz-se oportuna a análise documental. A forma escolhida por Webb para construir seus argumentos obedece à lógica de atrelar à crescente necessidade brasileira de mão-de-obra à chave retórica do projeto norte-americano de retirar de seu território os libertos. O objetivo almejado por ele, desta forma, era apresentar uma proposta irrecusável ao Brasil, por razões relacionadas não com qualquer projeto ou necessidade dos Estados Unidos, mas pelas próprias circunstâncias brasileiras.

As vantagens para o Brasil de alguns dos arranjos tais como o que sugiro são tão palpáveis, que não entrarei aqui no mérito da questão; mas quando necessário, torná-las visíveis para este governo, (como para vocês deve aparecer à primeira vista), caso eu seja autorizado a abrir negociações sobre o assunto em questão. Este comunicado visa demonstrar o que acredito ser um plano de colonização econômico e factível para os Estados Unidos ${ }^{46}$.

Como já mencionado, o argumento principal na exposição dos motivos relevantes que embasariam a constituição da companhia de colonização é o estado crônico de falta de mão-de-obra no Brasil, em especial nas províncias ao norte. Esse alicerce analítico fica claro no excerto a seguir:

\footnotetext{
45 "The United States stands ready to throw on the instant from ten to fifty thousands of her experienced and educated labourers upon the soil of Brazil, without price, if Brazil will but open wide her arms to receive them and provide for their future comfort!" Dispatch 17 to the Hon. W. H. Seward: UY - SAMR - JWWP, Caixa 8, Pasta 102.

46 "The advantages to Brazil, of some such arrangement as I suggest, are so palpable, that I will not here enter into a consideration of the subject; but when necessary, make them apparent to this Government, (as they must be at glance to you,) should I be authorized to open negotiations upon the subject in question. The object of this Communication is to demonstrate what I think would be a feasible and economical plan of Colonization to the United States". "Dispatch 17 to the Hon. W. H. Seward": UY - SAMR - JWWP, Caixa 8, Pasta 99. É preciso reafirmar que a este documento é uma cópia daquele que foi enviado ao Secretário de Estado dos Estados Unidos, William H. Seward, e não a que foi apresentada ao Brasil. O Despacho 17 é a base do documento entregue ao Brasil e por isso é possível retirar dele os eixos argumentativos de Webb. (Tradução nossa).
} 
O rápido aumento do valor do negro na província do Rio de Janeiro e em todas as províncias do sul do Império, além do avanço do preço do café somado ao indiscutível fato que a população escrava está em decréscimo, ao contrário da nossa que aumenta e que é de um tipo bastante inferior aos africanos trazidos para o Brasil - está rapidamente despovoando as províncias do norte do Império. Toda embarcação costeira traz de dez a trinta escravos para venda no Rio, para suprir a mão de obra nesta localidade e nas plantações de café: e o clamor é ouvido, vindo das províncias de Pará, Maranhan (sic), Piauhi (sic), Parahiba (sic), Pernambuco e até da Bahia que estas estão sendo despovoadas em favor das províncias do sul e da inevitável lei da oferta e da procura ${ }^{47}$.

O fio condutor que amarra as observações e críticas de Webb é a característica climática tropical do Brasil como fator ideal de adaptação e desenvolvimento para os trabalhadores afro-descendentes, motivação que já estivera presente nas negociações com os Estados da América Central. Em adição ao propício caráter tropical do Brasil, outro feixe importante de idéias que dá coesão interna à construção da proposta de Webb é a crença da impossibilidade completa de convivência entre raças diferentes, em liberdade, nos Estados Unidos. Essa impossibilidade - a qual se retornará ao longo do texto permeia toda a construção retórica de Webb e é a chave para compreender muitos aspectos de sua proposta.

\begin{abstract}
Não é apenas do interesse dos Estados Unidos e absolutamente necessário para sua tranqüilidade interna que se livre da instituição da escravidão, mas também, em conseqüência do preconceito de nosso povo contra a raça negra, se torna indispensável que o negro liberto seja exportado para fora de nossas fronteiras, pois conosco ele jamais poderá gozar de igualdade social ou política ${ }^{48}$.
\end{abstract}

A análise que Webb faz sobre o preconceito racial enquanto obstáculo para a inclusão de afro-descendentes na sociedade norte-americana está ligada a um racismo supostamente intransponível característico daquele país: "Deus formou no coração dos Estados Unidos da América (...) entre as raças branca e negra (...) o que torna absolutamente impossivel que estas raças possam viver juntas em termos de igualdade social e politica, ${ }^{\star A 9}$.

\footnotetext{
47 "The rapidly increasing value of the negro in the Province of Rio Janeiro (sic) and all the southern Provinces of the Empire, and the steadily advancing price of coffee, added to the well ascertained fact that the slave population is on the decrease instead of the increase, as with us, where the African is of a far lower type than those brought to Brazil, - is rapidly depopulating the Northern Provinces of the Empire. Every coasting vessel brings its ten to thirty slaves for sale at Rio, for the supply of labour in this vicinity and on the Coffee Plantations; and the cry is heard from the provinces of Para, Maranhan, Piaubi, Parabiba, Pernambuco, and even Babia, that they are being depopulated for the benefit of the Southern Provinces, by the inevitable law of demand and supply". Dispatch 17 to the Hon. W. H. Seward: UY - SAMR - JWWP, Caixa 8, Pasta 99. Grifos nossos. (Tradução nossa).

48 "It is not only the interest of the United States and absolutely necessary for her internal tranquility that she should get rid of the Institution of Slavery, but in consequence of the prejudices of our People against the African race, it is indispensable that the liberated Negro should be exported beyond our borders; because, he can never with us, enjoy social or political equality". Dispatch 17 to the Hon. W. H. Seward: UY - SAMR - JWWP, Caixa 8, Pasta 99. (Tradução nossa).

49 "God has built up in the hearts of the People of the United States of America (...) between the White and Black races (...) and which render it absolutely impossible, that the two races should live together on terms of social and political equality". "Memorial of General J. Watson Webb, a citizen of the United States, and Envoy Extraordinary and
} 
No Brasil, entretanto, tal realidade, na opinião de Webb, não se verificava, de modo que, dentre todos os lugares para os quais os ex-escravos dos Estados Unidos poderiam ser enviados, o Brasil era o único onde a inclusão social completa e a ascensão profissional e econômica se baseariam apenas nas capacidades de cada indivíduo e não na sua raça.

A constituição [do Brasil] reconhece como iguais [os afro-descendentes] dos homens brancos e igualmente elegíveis com ele aos mais altos cargos do império; e onde havia distinção social entre as raças branca e negra, que já existiu, esta quase foi erradicada. No banco do legislativo, na Marinha e no Exército, nas profissões de escolaridade e entre as profissões nas universidades, bem como no púlpito e nas relações sociais da vida, a cabeça encaracolada, e os lábios grossos dos descendentes da África têm seu lugar, lado a lado com seu "irmão branco" no Brasil e não pouco freqüentemente disputa com ele seu cargo ${ }^{50}$.

Para um estrangeiro recém chegado, talvez a estrutura das relações entre senhores e escravos no Brasil pudesse parecer mais harmoniosa do que de fato era. Entretanto, como se verá a seguir, o objetivo de Webb era convencer o governo dos Estados Unidos de que seu empreendimento tinha contornos verdadeiramente humanitários - além dos lucros possíveis advindos da necessária “solução" do problema racial. É possível pensar, contudo, que, para alguém que já vivia no Brasil há muitos meses, tornara-se perceptível que a violência racial estava sim presente nas relações sociais, mesmo que operando apenas em códigos diferentes daqueles dos Estados Unidos, o que demonstra a visível o caráter manipulador de sua redação ${ }^{51}$.

Por fim, uma última tática discursiva de Webb era que a sobreposição temporal dos problemas dos Estados Unidos e do Brasil só poderia ser obra da providência divina. Ao mesmo tempo em que crescia no Brasil, desde o fechamento do tráfico atlântico de escravos no início da década de 1850, o problema da mão-de-obra para atender à florescente economia do café; a Guerra da Secessão obrigava os Estados Unidos a enfrentar a emancipação geral de milhões de escravos. A linha que costura as análises da realidade brasileira e norte-americana, portanto, é a do ideário do destino manifesto.

Minister Plenipotentiary of the Government of the United States near the Court of Brazil, to his Imperial Majesty Dom Pedro II Perpetual Defender of Brasil”. UY - SAMR - JWWP, Caixa 8, Pasta 99. (Tradução nossa).

50 "The Constitution are recognized equals [os afro-descendentes] of the white man, and equally eligible with him to the highest offices of the Empire; and where already the social distinction between the white and Black races, which once existed, has been nearly eradicated. On the Bench in Legislative Halls, in the Army and the Navy; in the learned Professions and the among the professions in her Colleges; as also in the Pulpit and in the social relations of life, the wooly beaded and thick. lipped descendent of Africa, has his place side with his white "Brother" in Brazil, and not-unfrequently, jostles him from his position". Dispatch 17 to the Hon. W. H. Seward: UY - SAMR - JWWP, Caixa 8, Pasta 99. (Tradução nossa).

51 Ver DIAS, Maria Odila Leite da. Quotidiano e Poder em São Paulo no Século XIX. São Paulo: Editora Brasiliense, 1984. Embora a obra trate da província de São Paulo, desvenda muitos códigos diferentes de relação entre senhor e escravo. 
Deus criou nos corações do povo dos Estados Unidos da América, cujo solo e clima é propício ao trabalho escravo uma aversão à instituição da escravidão que resultou na maior guerra civil jamais vista no mundo; esta não terá um ponto final sem a emancipação de ao menos um milhão de escravos nos próximos cinco anos e de mais quatro milhões dentro de um período razoável(...). Quando já for manumisso o negro deverá ser transportado além da jurisdição dos Estados Unidos, onde ele jamais poderá gozar de igualdade política e social. O negro que está prestes a ser manumisso, foi treinado para o trabalho; é dócil e tratável, mas suspira por liberdade. Deus em Sua infinita sabedoria e misericórdia tornou possível através da política e interesses dos Estados Unidos e do Brasil assegurarlhe essa liberdade. O Brasil sofre pela falta de mão de obra. Quatro milhões de negros preparados para o trabalho, cada um valendo o equivalente a três africanos nativos, estão suspirando por liberdade e prontos para comprá-la no solo congenial do Brasil e sob as leis e instituições liberais brasileiras ${ }^{52}$.

A doutrina do destino manifesto envolve teorias que relacionam a predestinação dos norte-americanos à grandeza moral e territorial. A construção dessas idéias é múltipla e parte, em grande medida, de visões de mundo comuns em religiões protestantes como o calvinismo, batismo e metodismo, tão presentes nos Estados Unidos ${ }^{53}$. A expressão "destino manifesto", embora viesse se sedimentando desde a Revolução Americana ${ }^{54}$, foi popularizada por John O’Sullivan, em 1845, por ocasião das campanhas de anexação de novos estados como o Texas e o Oregon ${ }^{55}$ : "Nosso destino manifesto de expandir o continente, concedido pela providência para o livre desenvolvimento de nossos milhöes multiplicando por ano ${ }^{56}$ ".

52 "God has built up in the hearts of the People of the United States of America, whose soil and climate is congenial to slave labour a horror of the Institution of Slavery, which has resulted in the greatest Civil war the world has ever seen; and which can never be brought to a close without the emancipation of at least a million of slaves within the next five years, and of the whole four millions within a reasonable period (...) When manumitted therefore, there exists an absolutely necessity that the freed Negro should be transported beyond the jurisdiction of the United States, where he can never enjoy political or social equality. The Negro thus to be manumitted, has been trained to labour, is docile \& tractable but sighs for freedom. And God in His Infinite Wisdom and Mercy, has rendered it the policy and interest of the United States and Brazil to secure to bim that freedom. Brazil is absolutely suffering for Labour. Four millions of Negros educated to labour, each one of whom is worth three native Africans are sighing for Freedom and ready to purchase it on the genial soil and under the liberal laws \& Institutions of Brazil". On the necessity of supplying Brazil with Labour; and the policy of procuring free Black Labour from the United States: UY - SAMR - JWWP, Caixa 8, Pasta 102. (Tradução nossa).

53 HORSMAN, Reginald. Race and Manifest Destiny: The Origins of American Racial AngloSaxonism. Harvard University Press, Cambridge, 1981, pp. 81 e ss.

54 Por Revolução Americana entende-se o processo de independência de 13 colônias da Inglaterra: as províncias de New Hampshire; Massachusetts (que deu luz ao atual estado do Maine), Rhode Island e Connecticut (pertencentes à região da Nova Inglaterra); Nova York (de que se originou o atual estado de Vermont), Nova Jersey, Pennsylvania e Delaware (chamadas de colônias do meio ou Middle Colonies); Maryland e Virgínia (mais tarde, Virgínia, Kentucky e Virgínia do Oeste; chamadas de Colônia Chesapeak); Carolina do Norte (que originou o estado do Tenessee), Carolina do Sul e Geórgia. Os conflitos se iniciaram entre os anos 1763 e 1775, e a Guerra de Independência durou de 1775 a 1781. A Declaração de Independência dos Estados Unidos é de 1776. McCULLOUGH, David. 1776: A História dos Homens que Lutaram pela Independência dos Estados Unidos. Rio de Janeiro: Jorge Zahar, 2006.

55 John L. O’Sullivan era um importante jornalista político nos Estados Unidos do Século XIX. Sua contribuição para a cristalização da expressão "destino manifesto" no ideário político norte-americano se deu a partir de seu artigo "Annexation", publicado no Democratic Review, periódico do Partido Democrata. O’Sullivan contribuiu expressivamente para o debate da época de expansão das fronteiras dos Estados Unidos.

56 "Our manifest destiny to overspread the continent allotted by Providence for the free development of our yearly multiplying millions". ZINN, Howard. A People's History of the United States... p.137. 
O historiador Reginald Horsman acredita que as noções que mais tarde compuseram o conjunto mais sólido do destino manifesto envolvem idéias de cunho religioso e superioridade racial que já circulavam na Inglaterra no século XVII. Assim, afirma que no período colonial e na formação nacional dos Estados Unidos, depois de sua independência, esse tipo de pensamento esteve sempre presente como uma permanência.

Após a restauração a idéia de nação inglesa como eleitos cruzados de Deus pela vontade divina retrocedeu e idéias republicanas se tornaram uma linha menos importante do pensamento inglês. No entanto, os americanos nunca perderam a noção de que eram um povo eleito, um povo destinado a mudar o mundo para melhor (...). O sucesso da revolução americana deu ao povo americano um claro sinal de que haviam sido marcados pela providência para grandes feitos ${ }^{57}$.

Imerso neste ideário do destino manifesto, Webb argumentou que foi a providência divina que colocou Brasil e Estados Unidos no caminho um do outro. Alinhando os problemas e soluções de cunho econômico e social.

\begin{abstract}
Não existirá remédio para este mal, que agora se instala com tanta força sobre o Brasil? Creio que sim e que a providência está apontando a maneira de aliviar isso pelo que transcorre agora nos Estados Unidos. Em suma, a meu ver, o dedo de Deus aponta para as províncias do norte do Brasil como o futuro lar dos escravos manumissos dos Estados Unidos. O Brasil e o negro liberto irão ambos se beneficiar na mesma medida: um tratado entre os Estados Unidos e o Brasil, pelo qual todos os negros libertos dos Estados Unidos lá sejam agraciados com terras pelo governo do Brasil e ao término dos anos estabelecidos, se tornem cidadãos brasileiros com todos os direitos e privilégios da população negra livre do Império $^{58}$.
\end{abstract}

Para Webb, era a ausência de preconceito racial no Brasil umas das grandes provas divinas de que a expatriação dos afro-descendentes para a Amazônia era a única alternativa que reuniria o bem de todas as partes envolvidas no empreendimento: o Brasil se beneficiaria com trabalhadores experientes capazes de contribuir para o crescimento se sua economia; os Estados Unidos poderiam se veriam livres de seus ex-escravos, tendo em

57 "After the Restoration the idea of the English nation as the crusading agent of God's will faded, and republican ideas became less important thread in English thought, but the Americans never lost the belief that they were a special, chosen people, a people destined to change the world for the better (...) The successful American Revolution provided for the American People a powerful, overt sign that Providence had indeed marked them for great deeds". HORSMAN, Reginald. Race and Manifest Destiny: The Origins of American Racial Anglo-Saxonism. Harvard University Press, Cambridge, 1981 pp. 82-85. O período de Restauração que o autor se refere no trecho tratado é referente à experiência dos ingleses dentro da Revolução Inglesa a partir de 1642. (Tradução nossa).

58 "Is there no remedy for this great evil now pressing with such force upon Brazil? I think there is and that Providence is pointing out the mode of relief by the event now transferring in the United States. In one word, the finger of God, in my mind, points to the northern Provinces of Brazil as the future home of the manumitted Negro of United States, Brazil and the freed Negro, are all to be equally benefited by one and the same measure; a Treaty between the Unites States and Brazil, by which all the freed Negros of the Unites States, and there be endowed with land gratuitously by Brazil; and as the expiration of term of years, become citizens of Brazil, with all the rights and privileges of the free Negro population of the Empire". Dispatch 17 to the Hon. W. H. Seward: UY - SAMR - JWWP, Caixa 8, Pasta 102. (Tradução nossa). 
vista que Webb acreditava que o preconceito racial norte-americano jamais permitiria a convivência pacífica entre brancos e afro-descendentes iguais em direitos civis e políticos; e, por fim, os afro-descendentes poderiam se integrar de maneira verdadeira em uma nova sociedade onde suas características fenotípicas não seriam óbices para seu desenvolvimento pessoal.

\begin{abstract}
Sem dúvida o dedo da Providência está manifesto nessa extraordinária combinação de causas, que favorece no mesmo momento e praticamente sem custo, tanto os Estados Unidos como o Brasil. $1^{\circ}$ : o desembaraço por parte dos Estados Unidos de uma população que o país está pronto para libertar da servidão com custos de milhões de dolares. $2^{\circ}$ : uma ferramenta genial para o negro emancipado, que lhe garante, através de um curto período de aprendizado, sua liberdade, igualdade política e social e prosperidade financeira. $3^{\circ}$ : para o Brasil um suprimento necessário de mão de obra experiente num momento de tão grande necessidade que está em risco sua indústria e prosperidade. O primeiro objetivo do Brasil seria de assegurar para si esta mão de obra. Este memorial se propõe a indicar o modus operandi para que isso se realize. Tendo cumprido esta intenção, creio que o Brasil, em sua sabedoria, não poderá negar-se a seguir seu próximo passo, que deve ser de o de interromper o processo que agora ocorre de despovoamento de suas províncias do norte, através da implementação das primeiras importações de negros parcialmente emancipados ou "aprendizes", dos Estados Unidos para suprir a demanda de mão-de-obra nas províncias do sul do Império. Para tal, basta que o Brasil doe suas terras selvagens, no presente totalmente sem valor e fadadas a permanecerem assim para sempre, a não ser que se coloque nelas o trabalhador adequado para seu cultivo. Se esse trabalhador se tornar um homem livre e um cidadão do império, o tanto melhor para seu futuro e grandeza.
\end{abstract}

Como já introduzido, na década de 1860, a escravidão no Brasil, como instituição, já estava fadada ao seu fim, desde a proibição do tráfico pela lei de 1850, ainda que num horizonte de tempo relativamente distante. A substituição de mão-de-obra já ocupava algumas das grandes discussões nacionais e a reivindicação de imigrantes brancos tomava espaço dentro de um projeto de branqueamento da população, o que por só já indicava uma política ao preconceito racial enraizado no Brasil, na contramão do paraíso de igualdade racial que Webb enxergava ${ }^{59}$.

Os interesses por trás da retórica de Webb estavam ligados ao convencimento dos governos dos Estados Unidos e do Brasil em aderirem à sua proposta específica de "solução" para o "problema" dos ex-escravos norte-americanos. E possível que assim como ele tenha manipulado o encadeamento de seus argumentos para demonstrar que seria o Brasil quem lucraria mais com tal transferência de população - além do lucro pessoal, civil e político do liberto envolvido na transação - não seria de todo mal pensar que suas opiniões sobre a inexistência de preconceito racial no Brasil fizesse apenas parte desse jogo

59 Ver AZEVEDO, Célia Maria Marinho de. O Abolicionismo Transatlântico e a Memória do Paraíso Racial Brasileiro. Estudos Afro-Asiáticos, N. 30 (Dezembro, 1996). (Tradução nossa). 
de manipulação. Suas impressões sobre a convivência interracial nos Estados Unidos, entretanto, são reveladoras de estruturas de pensamentos arraigadas nas elites do Norte e do Sul do país, concepções essas que encontraram ecos políticos de segregação nos cem anos que se seguiram.

Bibliografia

1. ANDREW, N. e CLEVEN, N. Some Plans for Colonizing Liberated Negro Slaves in Hispanic America. The Journal of Negro History, Vol 11, N. 1, 1926.

2. AZEVEDO, Célia Maria Marinho de. Abolicionismo. Estados Unidos e Brasil, Uma História Comparada (século XIX). São Paulo: Annablume, 2003.

3. O Abolicionismo Transatlântico e a Memória do Paraíso Racial Brasileiro. Estudos Afro-Asiáticos, N. 30 (Dezembro, 1996).

4. BELL, Howard H. The Negro Emigration Movement, 1849-1854: A Phase of Negro Nationalism. The Phylon Quarterly, Vol. 20, N. 2, 1959.

5. BENNETT, Lerone. Forced Into Glory: Abraham Lincoln's White Dream. Chicago: Johnson Publishing Company, 2000.

6. BERLIN, Ira. The Structure of the Free Negro Caste in the Antebellum United States. Journal of Social History, Vol. 9, N. 3, 1976.

7. Gerações de Cativeiro: Uma História da Escravidão nos Estados Unidos. Rio de Janeiro: Record, 2006.

8. BOYD, Willis D. The American Colonization Society and the Slave Recaptives of 1860-1861: An Early Example of United States-African Relations. The Journal of Negro History, Vol. 47, N. 2, 1962.

9. BUENO, C \& CERVO, A. L. A Política Externa Brasileira (1822-1885). São Paulo: Ática, 1986.

10. BURIN, Eric. Slavery and the Peculiar Solution: A History of the American Colonization Society. Miami: University Press of Florida, 2005.

11. BURR, R. N. The Balance of Power in Nineteen-Century South America: An Exploratory Essay. Hispanic American Historical Review, Vol. 35, N. 1, 1955.

12. CAlógenas, J. P. A Política Exterior do Império. Brasília: Câmara dos Deputados, 1989.

13. CAMPOS, R. A. Relações Diplomáticas do Brasil de 1808 a 1902. Rio de Janeiro: Tipografia do Jornal do Comércio, 1913.

14. CARVAlHO, José Murilo de. A Construção da Ordem: a Elite Política Imperial; Teatro das Sombras: a Política Imperial. 2.ed. Rio de Janeiro: Editora UFRJ, Relume-Dumará, 1996.

15. CONRAD, Robert E. The Destruction of Brazilian Slavery, 1850-1888. Berkeley: The University of California Press, 1972.

16. COSTA, Emília Viotti da. Coroa de Glória, Lágrimas de Sangue: Rebelião dos Escravos em Demerara em 1823. São Paulo: Companhia das Letras, 1998.

17. Abolição. 8a Edição. São Paulo: UNESP, 2008.

18. CROUTHAMEL, James L. James Watson Webb: A Biography. Middletown: Wesleyan University Press, 1969.

19. DEGLER, Carl N. Slavery and the Genesis of American Prejudice. Comparative Studies in Society and History, Vol. 2, N. 1 (Outubro, 1959).

20. DIAS, Maria Odila Leite da Silva. O Fardo do Homem Branco: Southey, o Historiador do Brasil. São Paulo: Cia Editora Nacional, 1974.

21. Interiorização da Metrópole e Outros Estudos. São Paulo: Alameda, 2005.

22. DYER, Brainerd. The Persistence of the Idea of Negro Colonization. The Pacific Historical Review, Vol 12, N. 1, 1943.

23. FERRIS, Nathan L. The Relations of the United States with South America during the American Civil War. Hispanic American Historical Review, Vol. 21, N. 1 (Fevereiro, 1941). 
24. FONER, Eric. Nada Além da Liberdade: A Emancipação e seu Legado. Rio de Janeiro: Paz e Terra, 1988.

25. . Reconstruction: America's Unfinished Revolution, 1863-1877. Nova York: Perennial Classics, 2002.

26. FOSTER, Charles I. The Colonization of Free Negroes, in Liberia, 1816-1835. The Journal of Negro History, Vol. 38, N. 1 (Janeiro, 1953).

27. FREDRICKSON, George M. The Black Image in the White Mind. The Debate on Afro-American Character and Destiny, 1817-1914. Hanover: Wesleyan University Press, 1987.

28. GOLD, Robert L. Negro Colonization Schemes in Ecuador, 1861-1864. Phylon, Vol. 30, N. 3, 1969.

29. GOMES, Flávio dos Santos \& CUNHA, Maria Olívia Gomes da (orgs.). QuaseCidadão: Histórias e Antropologias da Pós-Emancipação no Brasil. Rio de Janeiro: Fundação Getúlio Vargas, 2005.

30. GOMEZ, Michael A. Reversing Sail. A History of the African Diaspora. Cambridge: Cambridge University Press, 2004.

31. GRADEN, Dale T. An Act "Even of Public Security": Slave Resistance, Social Terrorism, and the End of the International Slave Trade to Brazil, 1835-1856. Hispanic American Historical Review, Vol. 76, N. 2 (Maio, 1996).

32. GRESHAM, Luveta W. Colonization Proposals for Free Negroes and Contrabands During Civil War. Journal of Negro Education, Vol. 16, N. 1, 1947.

33. HILL, Lawrence F. Diplomatic Relations between the United States and Brazil. Durham: Duke University Press, 1932.

34. HODES, Martha. Sex, Love, Race. Crossing Boundaries in North American History. Nova York: New York University Press, 1999.

35. HORNE, Gerald. The Deepest South: The United States, Brazil and the African Slave Trade. Nova York: New York University Press, 2007.

36. HORSMAN, Reginald. Race and Manifest Destiny: The Origins of American Racial Anglo-Saxonism. Harvard University Press, Cambridge, 1981.

37. IOTTI, Luiza Horn (org). Imigração e Colonização: Legislação de 1747-1915. Porto Alegre: Assembléia Legislativa do Estado do RS: Caxias do Sul: EDUCS, 2001.

38. LITWAK, Leon. North of Slavery: The Negro in the Free States 1790-1860. Chicago: University of Chicago Press, 1961.

39. LOCKET, James D. Abraham Lincoln and Colonization: An Episode That Ends in Tragedy at L'Île de Vache, Haiti 1863-1864. The Journal of Black Studies, Vol. 21, N. 4, 1991.

40. LUZ, Nícia Vilela. A Amazônia para os Negros Americanos: Origens de uma Controvérsia Internacional. Rio de Janeiro: Saga, 1968.

41. MACHADO, Maria Helena Pereira Toledo. O Plano e o Panico: O Movimentos Sociais na Década da Abolição. Rio de Janeiro/São Paulo: UFRJ/Edusp, 1994. 42. (org.). Couto de Magalhães: Diário Íntimo. São Paulo: Companhia das Letras, 1998.

43. O Olhar Imperial sobre a América. Anais do XX 44. Simpósio da ANPUH (História: Fronteiras), Vol. 1, São Paulo, ANPUH, 1999. Brasil a Vapor: Raça, Ciência e Viagem no Século XIX. Tese de Livre-Docência, FFLCH, USP, 2005. 45. . (Ed.). Brazil Through the Eyes of William James: Letters, Diaries and Drawings, 1865-1866. Cambridge: David Rockefeller Center for Latin American Studies/ Harvard University Press, 2006. 
46. MAMIGONIAN, Beatriz G. In the Name of Freedom: Slave Trade Abolition, the Law and the Brazilian Branch of the African Emigration Scheme (BrazilBritish West Indies, 1830s-1850s). Slavery \& Abolition, 30:1, 2009.

47. MARTIN, Ben L. From Negro to Black to African American: The Power of Names and Naming. Political Science Quarterly, Vol. 106, N. 1, 1991.

48. MAY, Robert E. The Southern Dream of a Caribbean Empire, 1854-1861. Miami: University Press of Florida, 2002.

49. McPHERSON, James M. Battle Cry of Freedom: The Civil War Era. Nova York: Oxford University Press, 2003. The Negro's Civil War: How American Blacks Felt and Acted during the War for the Union. Nova York: Vintage Civil War Library, 2003.

51. MINTZ, Sidney W. e PRICE, Richard. O Nascimento da Cultura AfroAmericana: Uma Perspectiva Antropológica. São Paulo: Pallas, 2003.

52. MINTZ, Sidney W. Caribean Transformations. Nova York: Columbia University Press, 1989.

53. MOURA, Clóvis. Dicionário da Escravidão Negra no Brasil. São Paulo: Edusp, 2004.

54. NEEDEL, Jeffrey. The Abolition of the Brazilian Slave Trade in 1850: Historiography, Slave Agency and Statesmanship. Journal of Latin American Studies, N. 33, 2001.

55. PRATT, Mary Louise. Os Olhos do Império: Relatos de Viagem e Transculturação. Bauru: Edusc, 1999.

56. REIS, João José (org). Liberdade por um Fio: História dos Quilombos no Brasil. São Paulo: Companhia das Letras, 1996.

57. Rebelião Escrava no Brasil: A História do Levante dos Malês em 1835. Ed. Revista e Ampliada. São Paulo: Companhia das Letras, 2003.

58. ROTHMAN, Joshua D. Notorious in the Neighborhood: Sex and Families across the Color Line in Virginia, 1787-1861. Chapel Hill: The University of North Carolina Press, 2003.

59. SANNEH, Lamin. Abolitions Abroad: American Blacks and the Making of Modern West Africa. Cambridge: Harvard University Press, 2001.

60. SANTOS, Cláudio Villafañe G. Santos. O Brasil entre a América e a Europa: $O$ Império e o Interamericanismo. São Paulo: Unesp, 2004.

61. SCHEIPS, Paul J. Lincoln and the Chiriqui Colonization Project. The Journal of Negro History, Vol. 37, N. 4, 1952.

62. SHERWOOD, Henry Noble. Early Negro Deportation Projects. The Mississippi Valey Historical Review, Vol. 2, N. 4, 1916. The Formation of the American Colonization Society. The Journal of Negro History, Vol. 2, N. 3, 1917.

64. SCHWARTZ, Lilia. Nomeando as Diferenças: A Construção da Idéia de Raça no Brasil. In: BOAS, Glaucia Villas \& GONÇALVES, Marco Antonio (orgs). O Brasil na Virada do Século. Rio de Janeiro, Relume/Dumará, 1995.

65. SEIFMAN, Eli. Education or Emigration: The Schism within the African Colonization Movement, 1865-1875. History of Education Quarterly, Vol. 1, N. $1,1967$.

66. SCHOONOVER, Thomas. Misconstrued Mission: Expansionism and Black Colonization in México and Central America During Civil War. The Pacific Historical Review, Vol. 49, N. 4, 1980.

67. . The Mexican Lobby: Matías Romero in Washington, 1861-1867. Lexington: University of Kentucky Press, 1986.

68. TENZER, Lawrence. The Forgotten Causes of the Civil War: New Look at the Slavery Issue. New Jersey: Scholar's Publishing House, 1997. 
69. WESLEY, Charles H. Lincoln's Plan for Colonizing the Emancipated Negroes. The Journal of Negro History, Vol 4, N. 1, 1919. 